\title{
COMPARATIVE ANALYSIS OF SPECTRAL AND ILLUMINANCE OF INCANDESCENT LAMPS AND WHITE LIGHT EMITTING DIODES IN SAUDI ARABIA MARKET
}

\author{
Manal A. Haridy ${ }^{1}$, Hissah S. Al-Baqawy ${ }^{2}$, Maryam S. Alshammary ${ }^{3}$, Mona A. Alshammary ${ }^{4}$ \\ ${ }^{1}$ Photometry and Radiometry Division, National Institute of Standards (NIS), Giza, Egypt \& Physics \\ Department, College of Science, University of Hail (UOH), P. O. Box2440 Hail, Saudi Arabia. \\ ${ }^{2}$ Physics Department, College of Science, University of Hail (UOH), P. O. Box2440 Hail, Saudi Arabia \\ ${ }^{3}$ Physics Department, College of Science, University of Hail (UOH), P. O. Box2440 Hail, Saudi Arabia \\ ${ }^{4}$ Physics Department, College of Science, University of Hail (UOH), P. O. Box2440 Hail, Saudi Arabia
}

\begin{abstract}
The present comparative study aimed to investigate some lighting characteristics of the most useable commercial lamps in the Saudi Arabia markets; New Power white light emitting diode lamps (WLEDs) and compare it Osram incandescent lamps. The lighting characteristics such as spectral power distributions (SPDs), illumination levels, ratio of illuminance to electrical power and Spectral mismatch correction factor (SCF) to human response eye curve $V(\lambda)$ have important roles on visual health effects of lighting for the two groups of the lamps. The first measurements set up based on NIS Spectroradiometer and photometric bench to measure for measuring spectral power distribution (SPDs) for the two groups of lamps. The second measurements set up based on Luxmeter and photometric bench for measuring illuminance for the two groups of lamps. Calculations of comparative analysis have been done for spectral power distributions (SPDs), illumination levels, ratio of illuminance to electrical power and Spectral mismatch correction factor (SCF) to human response curve $V(\lambda)$. The SPDs diagrams for the WLEDs showed typical light emitting diode response, with a few narrow spectral peaks. Moreover, the incandescent lamps showed high power in the longer wavelengths of the visible spectrum. The histogram for comparison of Spectral Mismatch Factor shows that for the two groups of the group of WLEDs lamps is higher than the group of incandescent lamps. According to that, the group of incandescent lamps is better matching than the group of WLEDs lamps. The illuminance values show that the group of incandescent lamps is higher in illuminance level than the group of WLEDs lamps. But the illuminance per electrical wattages for the two groups of lamps is higher in the group of WLEDs lamps than the group of incandescent lamps. This is means that the group of WLEDs lamps is more savers in energy than the group of incandescent lamps. We recommended using WLEDs lamps for economically and energy saves. On the other hand, we recommended using incandescent lamps for perfectly spectral matching with human response eye curve $V$ ( $\lambda$ ). Data analysis was performed and uncertainty model includes all parameters accompanied with the measurements are calculated.
\end{abstract}

Keywords: Uncertainty, Illuminance, Spectral Power Distribution(SPD)Spectral mismatch correction factor(SCF), White light emitting diode lamps (WLEDs), Incandescent Lamps. $* * *$

\section{INTRODUCTION}

Lighting researches tried to identify better solutions for achieving good artificial lighting [1,2]. In this way, new lighting sources and lighting system designs have been developed [3].Enormous energy savings are possible using energy efficient equipment, effective controls, and careful design. Using less electric lighting reduces heat gain, thus saving air-conditioning energy and improving thermal comfort. The incandescent light bulb has been the most popular light bulb for decades but it will soon be discontinued because there are new light bulbs that use less energy, produce less heat, and produce a brighter light of different colors. Incandescent lamps are commonly known as (incandescent) light bulbs. They have relatively short lives (typically 1000 to 2000 hours of use) and are the least efficient of common light sources.
The incandescent light bulbs had lit up our life since the beginning of the Twentieth Century, when they superseded the first electric lamps, which were the carbon-arc lamps as shown in Figure 1 [4]. In the incandescent bulbs, a large part of the power consumed is converted into heat rather than visible light [5].Since other electrical light sources are more effective, the incandescent bulbs raise some financial and ecological concerns [6].

Today, the solution for a better lighting system seems to be the use of LEDs. The light-emitting diodes, LEDs, have been known for many years. They are based on the electroluminescence, which is the production of light by the flow of electrons. This phenomenon was discovered in 1907 by H.J. Round of Marconi Laboratories, who used a crystal of silicon carbide $(\mathrm{SiC})$ and a cat's-whisker detector to show it $[8,9$.$] .$ 


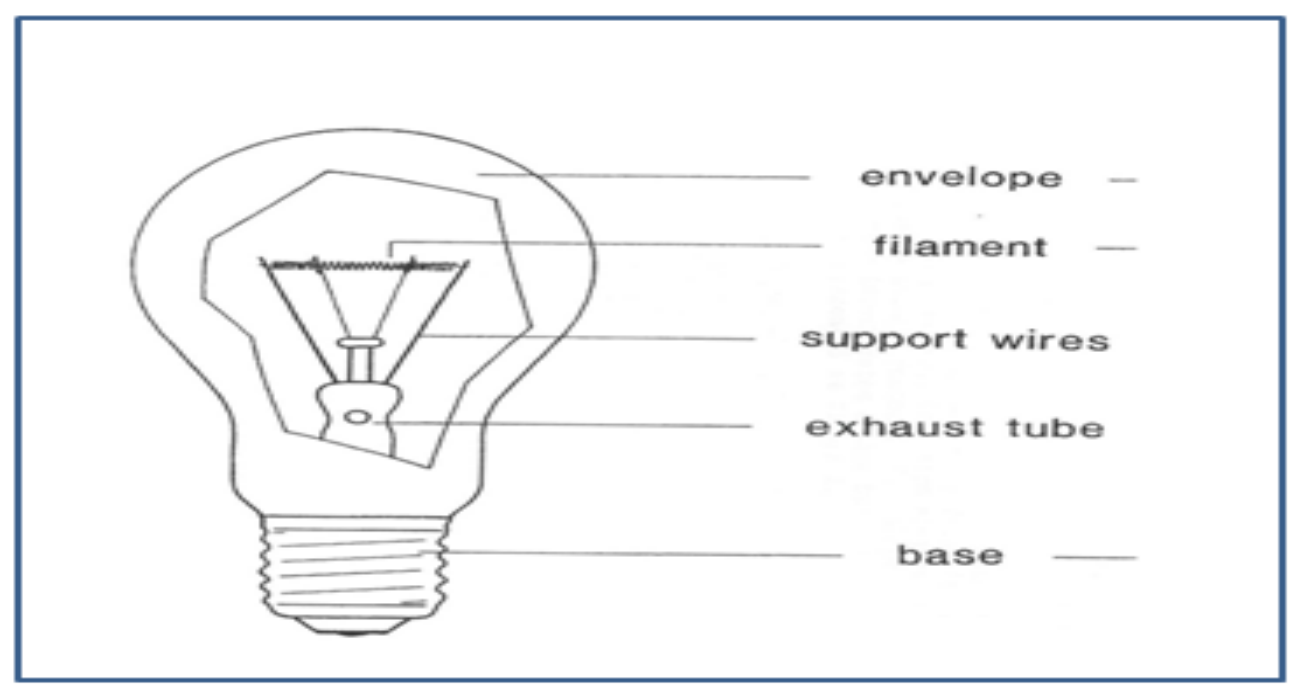

Fig 1: Typical Incandescent lamp showing coil mount structure [4,7]

To produce white light, as shown in Figure 2, most currently available LED luminaire employ phosphor coated blue LEDs or, less commonly, various combinations of red, green and blue (RGB) LEDs. Although performance varies widely among available general service LED lamps, the technology continues to improve even as the price per lumen decreases.

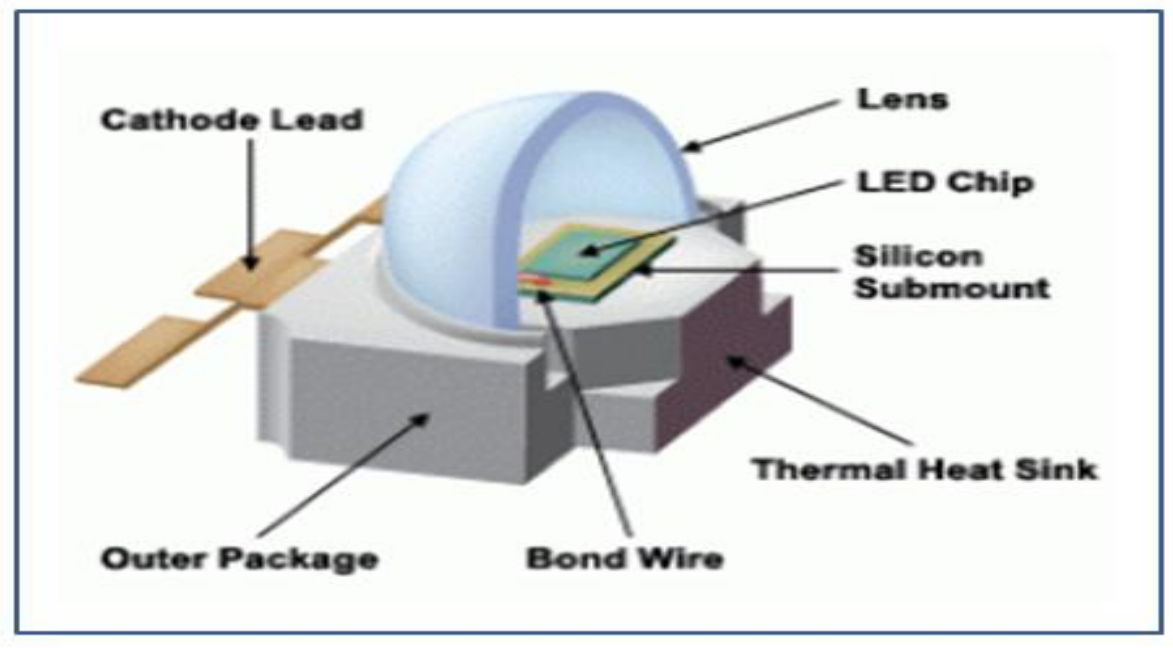

Fig 2: .Structure of LED Lamps.

Some LED products have already demonstrated equivalence to the ubiquitous 60 Watt incandescent light bulb, and higher output alternatives to 75 Watt and 100 Watt incandescent. When chosen carefully, LED products can offer substantial energy savings without compromise to the quantity or quality of illumination, while also saving money in the long run. [10]. This is the result of radiative recombination of electrons and holes, where the excited electrons release energy as photons [11].Photometric measurements with LEDs require greater care than such measurements with conventional light sources. Commission Internationale de 10Eclairage (CIE) has recommended guidelines for LED photometric measurements, which deal with measurement geometry, detector requirements, calibration procedure, etc. [12].Light-emitting diode (LED) lighting offers many potential benefits over incandescent. Serving as a long-life solid-state lighting source, LEDs have been proposed to replace the light sources in some special applications of the automotive, lighting, display and new lighting developments $[13,14]$. Recently, colored and white LEDs are used as possible standard sources in the photometric or spectrophotometric areas of the optical metrology [15-18].

Spectral power distribution (SPD) is used for describing visible spectrum of lighting sources. This quantity shows the radiant power emitted by the source at each wavelength over the visible region (380 to $760 \mathrm{~nm}$ ). Lamp manufacturers present the SPD curves of specific light sources. The incandescent lamp frequently has high power in the longer wavelengths (above $650 \mathrm{~nm}$ ) of the visible spectrum and 
therefore, effectively renders red colors. The light emitting diode lamp has high power in the short wavelength of the visible spectrum (below $450 \mathrm{~nm}$ ) [19,20]. According to that, An error occurs when a photometer head measures a light source having the relative spectral power distribution (SPDs) different from the calibrated source. The spectral error can be taken into account through a spectral mismatch correction factor [21-23].

$$
S C F=\frac{\int_{360}^{830 n m} P_{e}^{T}(\lambda) \times V(\lambda) d \lambda \int_{\text {all-wavelengths }} P_{e}^{S}(\lambda) \times R(\lambda) d \lambda}{\int_{\text {all-wavelengths }} P_{e}^{T}(\lambda) \times R(\lambda) d \lambda \int_{360}^{830 n m} P_{e}^{S}(\lambda) \times V(\lambda) d \lambda}
$$

where

$P_{e}^{T}(\lambda):$ is the relative spectral output of the test source.

$P_{e}^{S}(\lambda):$ is the relative spectral output of the standard source.

$R(\lambda)$ : is the relative spectral responsivity of the photometer.

$V(\lambda)$ : is the spectral luminous efficiency function.

\section{METHODS}

In the present research, the study of two groups of lamps including New Power white light emitting diode lamps (WLEDs) and Osram incandescent lamps commercially available to the Saudia Arabia consumers. Lighting characteristics including spectral power distribution were measured usingmini-spectrometer for relative spectral power distribution and standard radiometer for absolute irradiance measurement from lamps is used, respectively. A minispectrometer, Model C10082CA [24] from Hamamatsu, with appropriate input optics (monochromator with optical fiber and CCD image sensor)at National Institute of Standards (NIS) is used as a wavelength tunable-filter radiometer to evaluate the spectral power distribution, shown schematically in Figure 3.It measured directly using the photometric bench and spectroradiometer to evaluate the spectral power distribution. Light to be measured is guided into entrance port of spectroradiometer through an optical fiber and the spectrum is output through the USB port to a PC for a data acquisition. An optical fiber that guides light input from White light emitting diode and Incandescent lamps allows a flexible measurements setup. The spectroradiometric measurement of light sources was performed based on CIE 63-1984 method recommended by International Electrotechnical Commission (IEC) [25]. The employed spectroradiometer is periodically calibrated using a standard source of irradiance based on standard method [26]. Spectroradiometers are the most accurate for measuring spectral energy distribution of any light source. In this way, the studied lamps were separately installed at a distance of half a meter above the spectroradiometer and then after five minutes, the interested data for each lamp was registered. Measurements were performed in a conditioned dark room and maintaining the temperature at $(25 \pm 2)^{0} \mathrm{C}$.

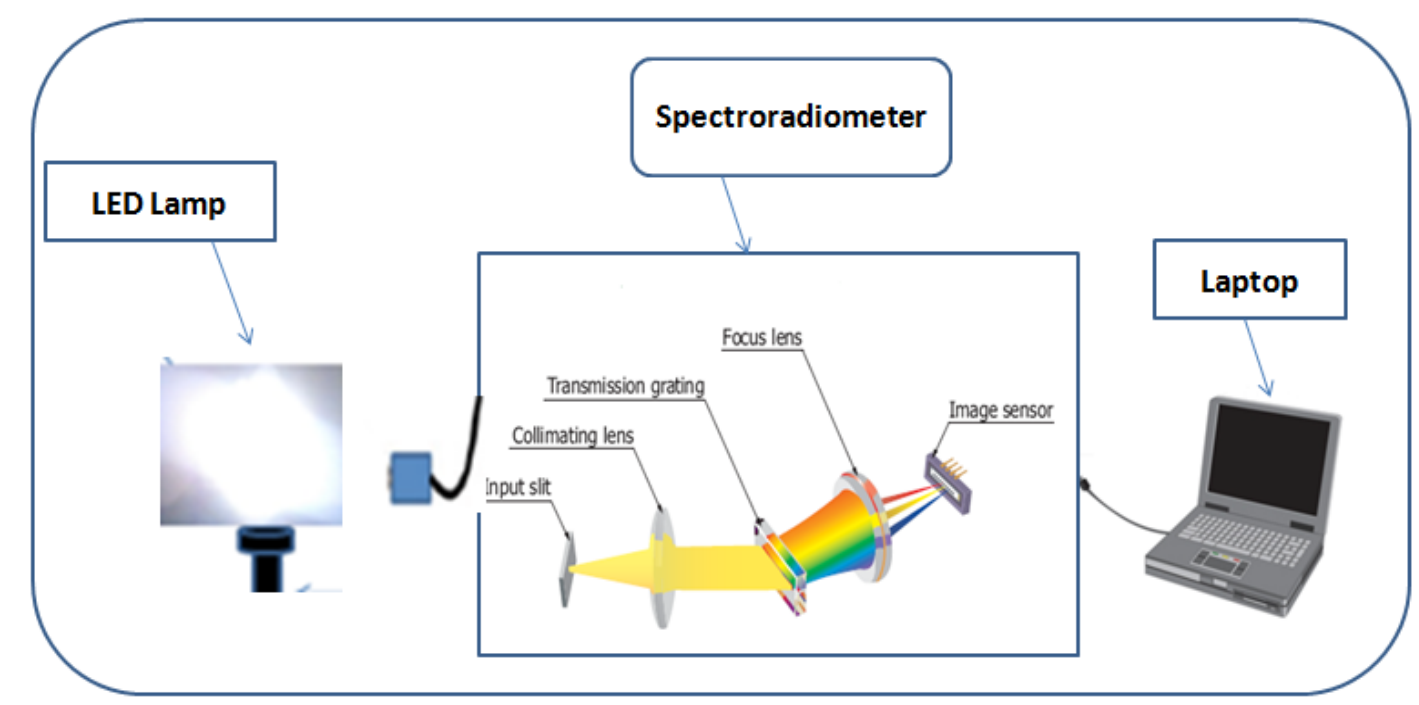

Fig 3: NIS setup for measuring the spectral power distribution based on mini-spectrometer from Hamamatsu [24].

The illuminance of each lamp is measured using a Luxmeter TM-201Lux as shown in Figure 4. Measurements were performed in a conditioned dark room and maintaining the temperature at $(25 \pm 2)^{0} \mathrm{C}$. The Luxmeter was mounted on a translation stage and positioned at the same height as the light source (WLEDs and incandescent) on the optical bench. Prior to taking measurements, each lamp was warmed up to 30 minutes. Measurements were repeated for each lamp and were finally averaged out. The uncertainty in irradiance measurements is calculated. 


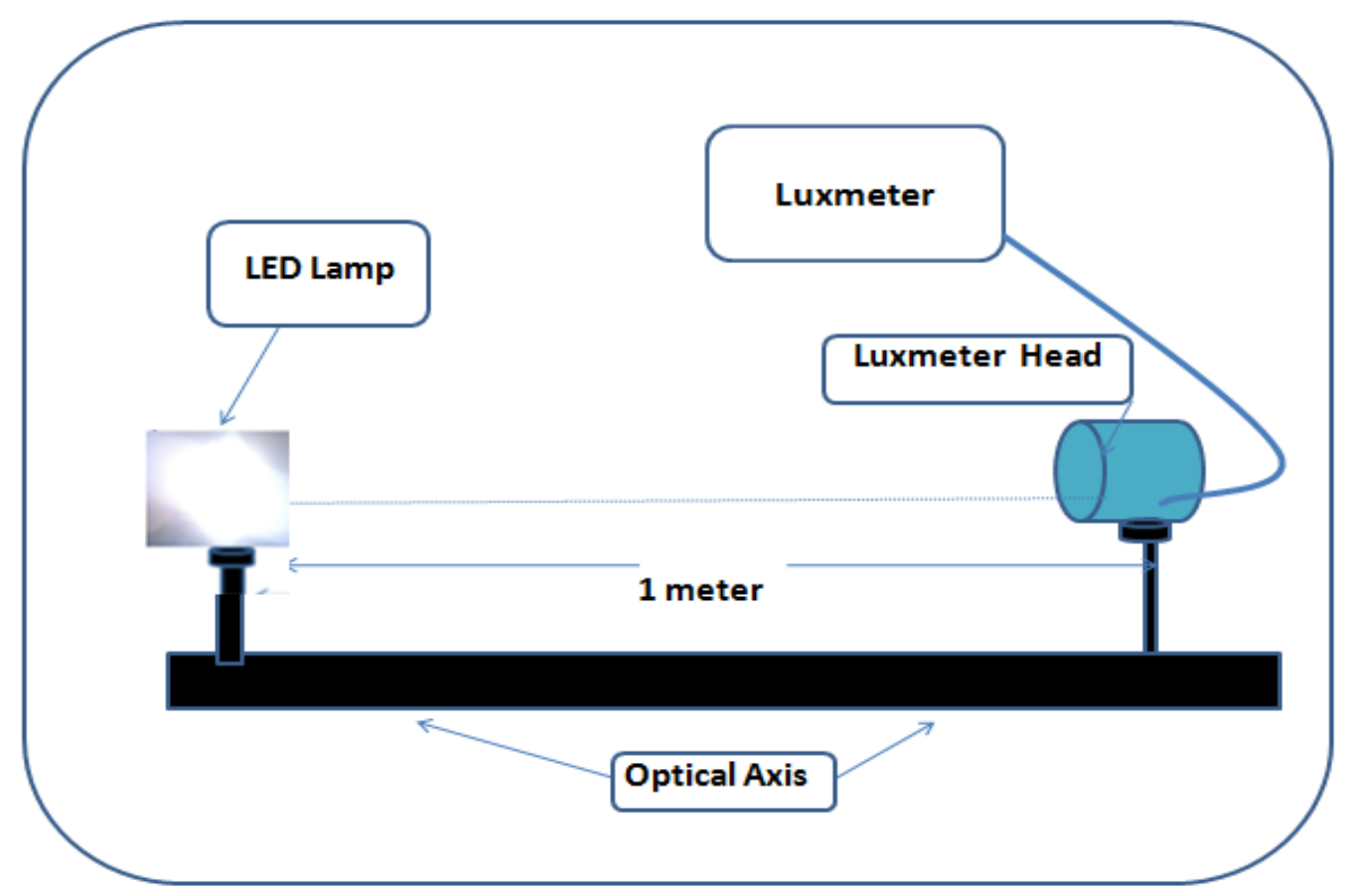

Fig 4: Schematic diagram of facility for measuring illuminance for WLEDs and Incandescent Lamps.

\section{RESULTS AND DISCUSSIONS}

A setup based on two NIS spectral radiometers and photometric bench for the spectral power distribution of two groups of lamps, three New Power 3 watt white light emitting diode lamps (LED-1-UOH, LED-2-UOH and LED3-UOH) and two Osram100 watt incandescent lamps (Osram-1-UOH, Osram-2-UOH and Osram-3-UOH).The relative spectral power distribution was normalized for each lamp so we can compare the lamps as shown in Figure 5.

Figure (5) shows the spectral power distribution SPDs at each wavelength over the visible region of two groups of lamps, three New Power 3 watt white light emitting diode lamps (LED-1-UOH, LED-2-UOH and LED-3-UOH) and two Osram 100 watt incandescent lamps (Osram-1-UOH, Osram-2-UOH and Osram-3-UOH).It is used for describing visible spectrum of lighting sources. This quantity shows the radiant power emitted by the source at each wavelength over the visible region (380 to $760 \mathrm{~nm}$ ). The SPDs diagrams for the WLEDs showed typical light emitting diode response, with a few narrow spectral peaks. Moreover, the incandescent lamps showed high power in the longer wavelengths of the visible spectrum. It is found that each group of lamps has its own characteristics and they emit their spectrum in the visible region with different spectral distributions for each of the two groups. 


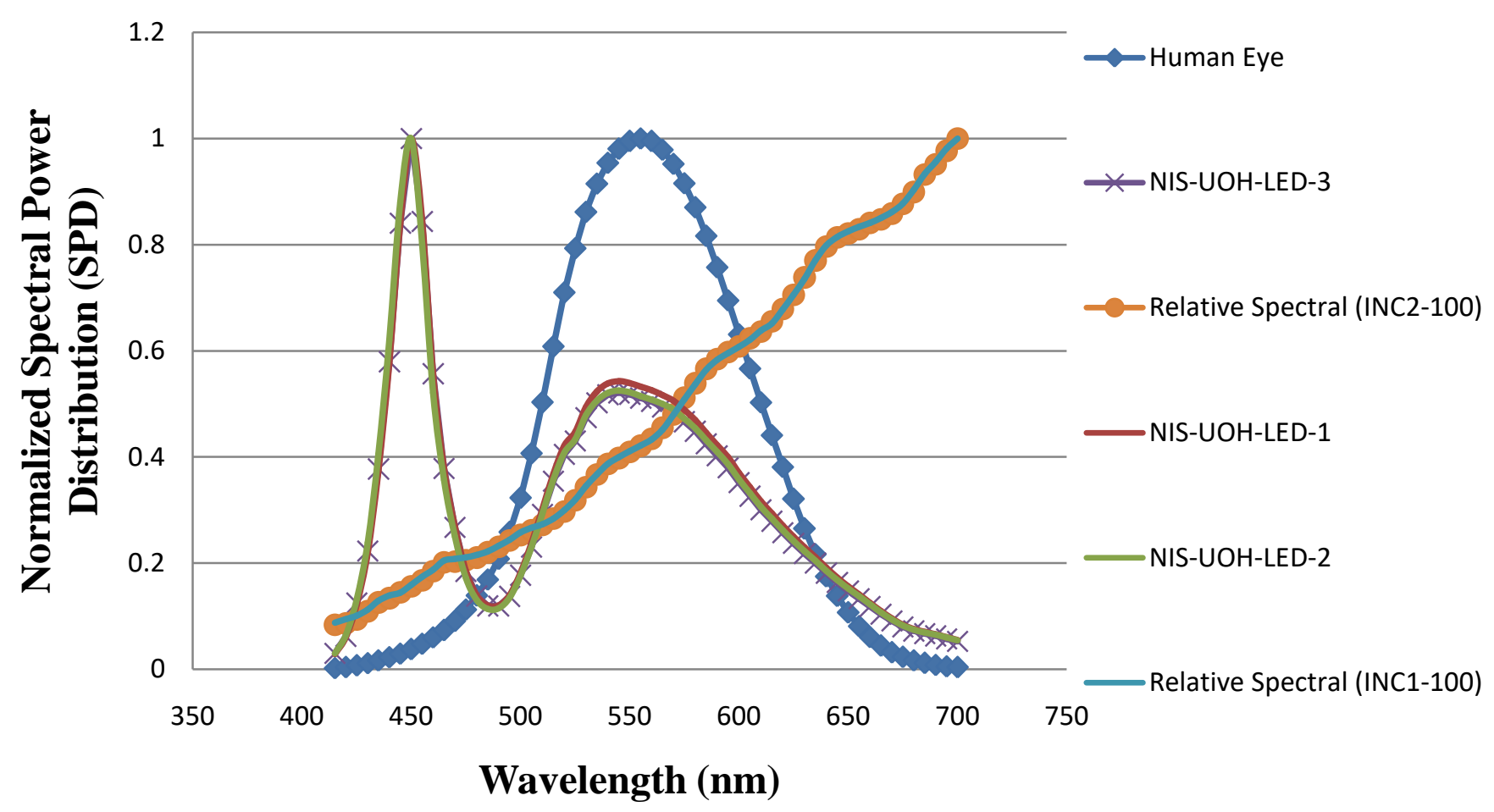

Fig 5: The responsivity of human eye $V(\lambda)$ Curve and the spectral power distributions of the LEDs and Incandescent Lamps.

Figure 6.shows the histogram for comparison of Spectral Mismatch Factor (SCF) of the two groups of lamps, three New Power 3 watt white light emitting diode lamps (LED-1UOH, LED-2-UOH and LED-3-UOH) and two Osram 100 watt incandescent lamps (Osram-1-UOH, Osram-2-UOH and Osram-3-UOH). It has been calculated from the equation (1). We found that for the two groups of the group of WLEDs lamps is higher than the group of incandescent lamps. According to these results, the group of incandescent lamps is better matching than the group of WLEDs lamps.

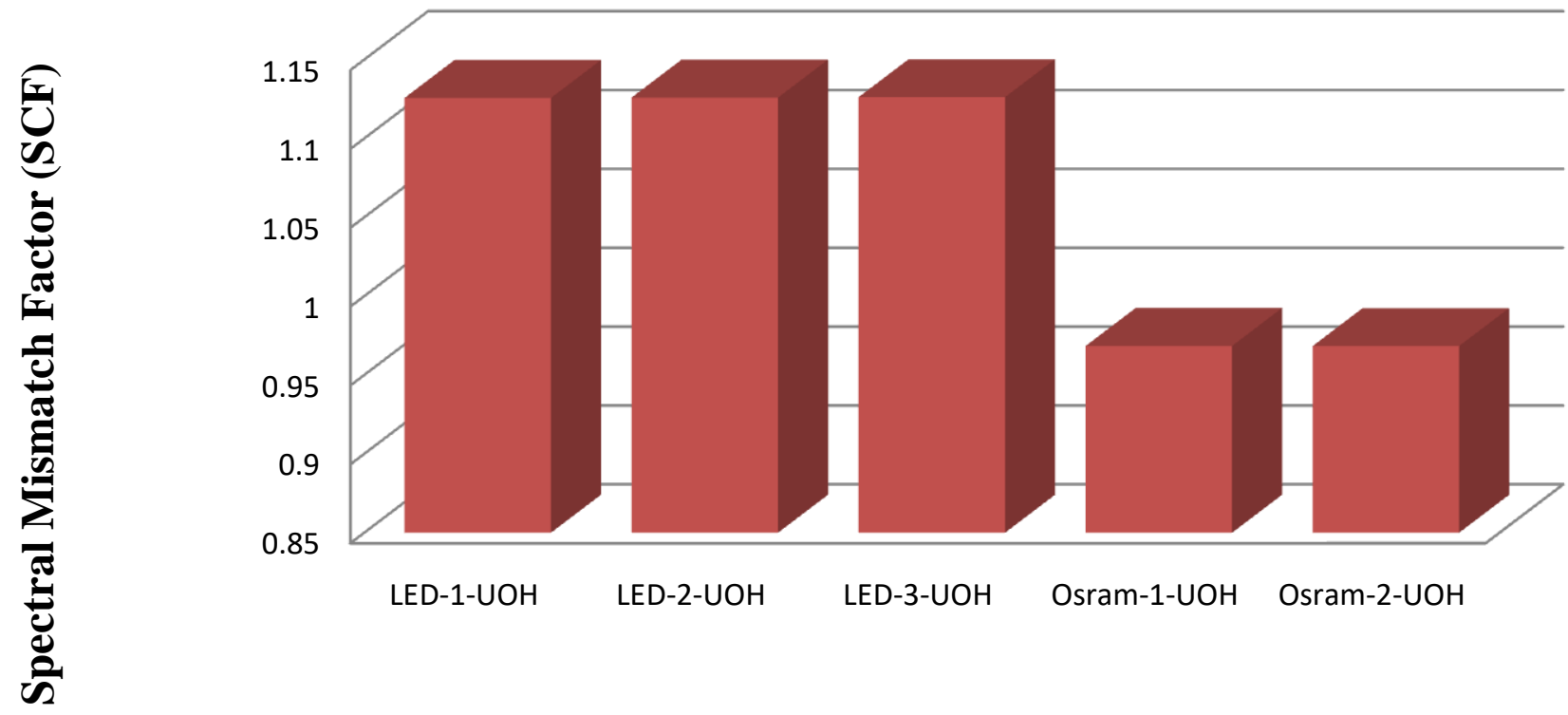

\section{Types of Lamps}

Fig 6:.Spectral Mismatch Factor of the LEDs and Incandescent Lamps. 
Figure 7.shows the histogram for comparison of illuminance values at distance 1 meter between the lamps and the Luxmeter. As it is obvious, the group of incandescent lamps is higher in illuminance level than the group of WLEDs lamps.

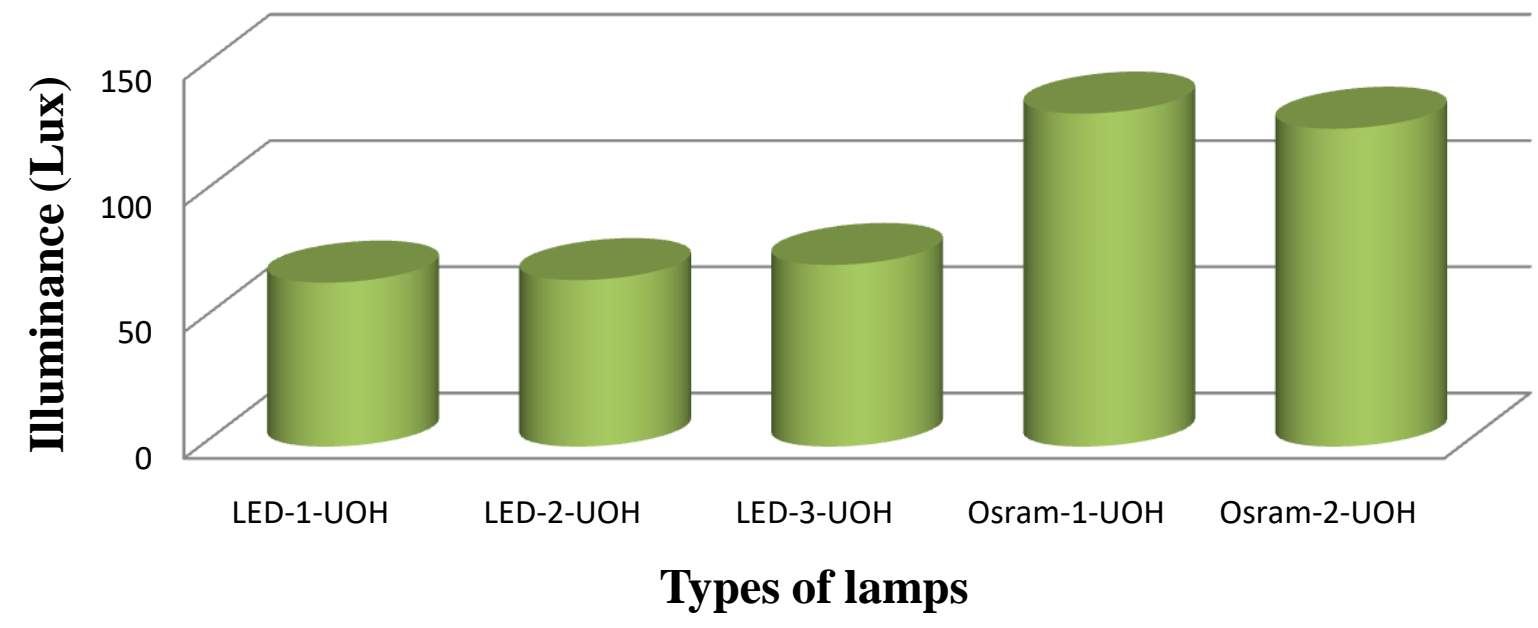

Fig 7: The Illuminance measurements of LEDs and Incandescent lamps.

To make a better comparison in illuminance levels, it would be more appreciate to analyze illuminance per electrical wattages for the two groups of lamps as shows in Figure 8. It is obvious that the ratio of illuminance level per electrical power is higher in the group of LEDs lamps than the group of incandescent lamps. This is means that the group of LEDs lamps is more savers in energy thanthe group of incandescent lamps.

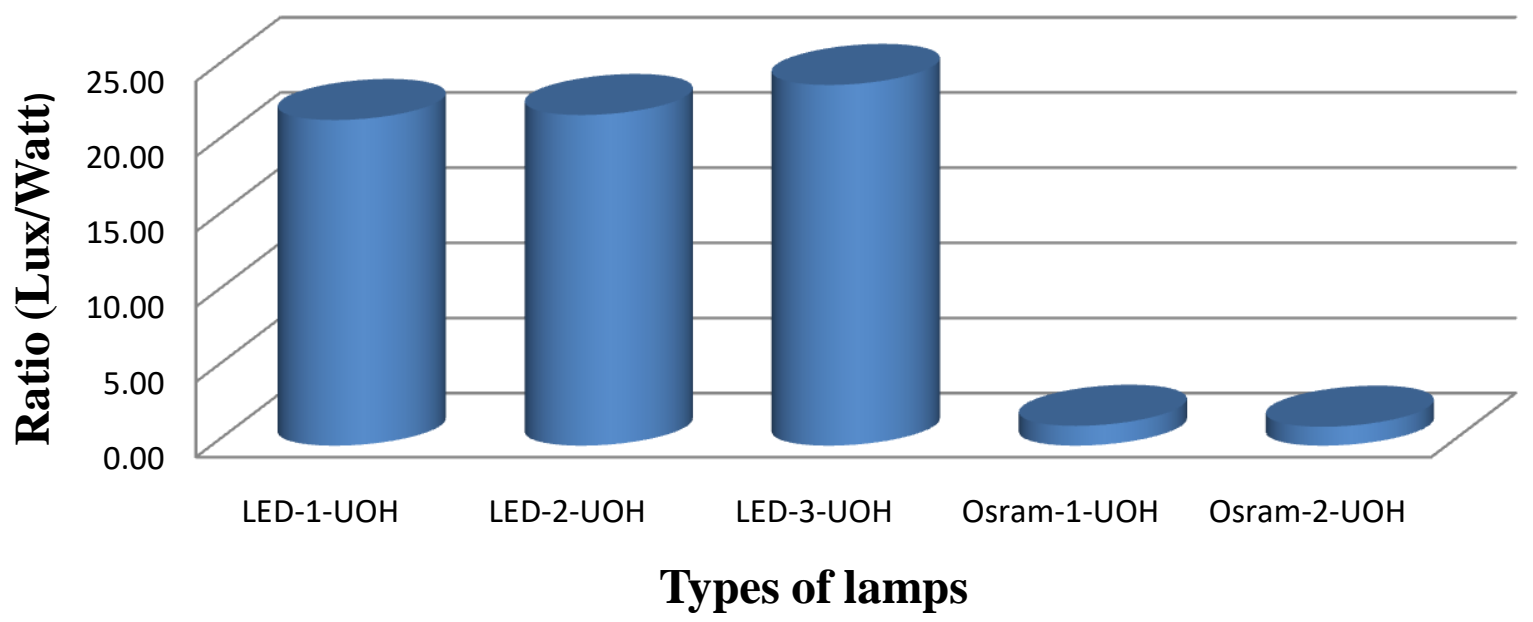

Fig 8: Ratio of Illuminance (Lux) to power (Watt) at 1 meter distance for LEDs and Incandescent lamps.

\section{UNCERTAINTY ANALYSIS}

Evaluation of the uncertainty is done by the Guide to the expression of uncertainty in Measurement (GUM)method. This method is adopted and described in details by
International Organization for Standardization (ISO) [27]. The standard uncertainty $u\left(x_{i}\right)$ to be associated with input quantity $\mathrm{xi}$ is the estimated standard deviation of the mean $[27,28]$. 


$$
u\left(x_{i}\right)=s(\bar{X})=\left(\frac{1}{n(n-1)} \sum_{k=1}^{n}\left(X_{i, k}-\bar{X}\right)^{2}\right)^{1 / 2}
$$

The combined standard uncertainty uc(y) is obtained by combining the individual standard uncertainties $u_{i}$ these can be evaluated as Type A and Type B. That is,

$$
u_{c}^{2}(y)=\sum_{i=1}^{N}\left(\frac{\partial f}{\partial x_{i}}\right)^{2} u^{2}\left(x_{i}\right)
$$

The accompanied uncertainty of the spectral power distribution (SPDs) measurements for the WLEDs lamps and the incandescent lamps is equal to11\%as shown in Table 1, and the illuminance measurements for the WLEDs lamps and the incandescent lamps is equal to12\%as shown in Table 1.

Table 1: Estimated Uncertainty of spectral power distribution for theWLEDs lamps and the incandescent lamps.

\begin{tabular}{|l|l|}
\hline Uncertainty Component & $\begin{array}{l}\text { Relative Standard } \\
\text { Uncertainty (\%) }\end{array}$ \\
\hline $\begin{array}{l}\text { Calibration of } \\
\text { spectroradiometer }\end{array}$ & 5.5 \\
\hline Distance measurements & 0.015 \\
\hline Lamp Regulation & 0.001 \\
\hline Repeatability Expanded & 0.02 \\
\hline $\begin{array}{l}\text { Relative } \\
\text { Uncertainty }(\boldsymbol{k}=\mathbf{2})\end{array}$ & $\mathbf{1 1 \%}$ \\
\hline
\end{tabular}

Table 2: Estimated Uncertainty budget of illuminance for theWLEDs lamps and the incandescent lamps.

\begin{tabular}{|l|l|}
\hline Uncertainty Component & $\begin{array}{l}\text { Relative Standard } \\
\text { Uncertainty (\%) }\end{array}$ \\
\hline $\begin{array}{l}\text { Illuminance responsivity } \\
\text { calibration of standard } \\
\text { photometer }\end{array}$ & 6 \\
\hline Distance measurements & 0.015 \\
\hline Lamp Regulation & 0.001 \\
\hline Repeatability Expanded & 0.025 \\
\hline $\begin{array}{l}\text { Relative } \\
\text { Uncertainty }(k=2)\end{array}$ & $\mathbf{1 2 \%}$ \\
\hline
\end{tabular}

\section{CONCLUSION}

Lighting comfort is a main factor affecting our ability to perform tasks in closed spaces. Some characteristics of lighting sources can effect on quality of lighting. White light emitting diode lamps can be employed for homes usage and for offices rooms. The SPDs diagrams for the WLEDs showed typical light emitting diode response, with a few narrow spectral peaks. Moreover, the incandescent lamps showed high power in the longer wavelengths of the visible spectrum. The histogram for comparison of Spectral Mismatch Factor shows that for the two groups of the group of WLEDs lamps is higher than the group of incandescent lamps. According to that, the group of incandescent lamps is better matching than the group of WLEDs lamps. The illuminance values show that the group of incandescent lamps is higher in illuminance level than the group of WLEDs lamps. But the illuminance per electrical wattages for the two groups of lamps is higher in the group of WLEDs lamps than the group of incandescent lamps. This is means that the group of WLEDs lamps is more savers in energy than the group of incandescent lamps. Data analysis was performed and uncertainty model includes all parameters accompanied with the measurements are calculated. The accompanied uncertainty of the spectral power distribution (SPDs) measurements for the WLEDs lamps and the incandescent lamps is equal to $11 \%$ and the illuminance measurements for the WLEDs lamps and the incandescent lamps is equal to $12 \%$. We recommended using WLEDs lamps for economically and energy saves. On the other hand, we recommended using incandescent lamps for perfectly spectral matching with human response eye curve $\mathrm{V}(\lambda)$.

\section{ACKNOWLEDGEMENT}

I would like to thanks Dr.Sameh M. Reda (Photometry and Radiometry Division) to provide assistance in this work.

\section{REFERENCES}

[1]. Davis W. Measuring color quality of light sources. 6th International Conference on Solid State Lighting; September 12; California,2006.

[2]. Hoffmanna G, Guflera V, Griesmacherb A, Bartenbach C, Canazeic M, Stagglc S, et al. Effects of variable lighting intensities and colour temperatures on sulphatoxymelatonin and subjective mood in an experimental office workplace. ApplErgon.; 39:719-728,2008.

[3]. OhnoY.Optical metrology for LED and solid state lighting.Fifth Symposium Optics in Industry; September 89; Santiago de Queretaro; 2006.

[4]. A.C. Sparavigna, Carbon-Arc Light as the Electric Light of 1870, International Journal of Sciences, Volume 3, Issue 10 , pages $1-7,, 2014$.

[5]. S. Speight, LED Industry and Lighting Technologies, ISG Illuminations System Inc.,2010

[6]. A.C. Sparavigna, Carbon Dioxide Concentration and Emissions in Atmosphere: Trends and Recurrence Plots, International Journal of Sciences, Volume 3, Issue 10,pages 8-15, 2014.

[7]. Comission Internationale de Eclairage. Electric Light Sources State of Art-1987, CIE 77, 1988.

[8]. H.J. Round, A Note on Carborundum, Electrical World, 1907, Volume XLIX, Issue 6, page 309.

[9]. N. Zheludev, The Life and Times of the LED - A 100Year History, Nature Photonics, Volume 1, Issue April, pages 189- 192,2007.

[10]. U.S. Department of Energy,Energy Efficiency and Renewable Energy,"Comparing White Light LEDs to Conventional Light Sources", April, 2012.

[11]. J. Li, J. Wang, Z. Liu and A. Poppe, Solid-State Physics Fundamentals of LED Thermal Behavior, in Thermal Management for LED Applications, Clemens J.M. 
Lasance and AndrásPoppe Editors, Springer Science \& Business Media, 17/set/, pages 15-24,2013.

[12]. Comission Internationale de 10Eclairage. Measurement of LEDs, CIE 127, 1997.

[13]. Kaminski MS, Garcia KJ, Stevenson MA, Frate M, Koshel RJ. Advanced topics in source modeling .Proc SPIE;4775:46-57,2002.

[14]. Zerfhau-Dreiho“ fer H, Haack U, Weber T, Wendt D. Light source modeling forautomotive lighting devices.Proc SPIE;4775:58-66,2002.

[15]. Steven W, Brown W, Santana C, Eppeldauer GP. "Development of a tunable LED-based colorimetric source". J Res NatlInst Stand Technol;107:363-71,2002.

[16]. Park S, Kim YW, Lee DH, Park SN. "Preparation of a standard light-emitting diode (LED) for photometric measurements by functional seasoning". Metrologia;43:299-305. Jones CF,2006.

[17]. Ohno Y. Colorimetric accuracies and concerns in spectroradiometry of LEDs. In: Proceedings of CIE symposium, CIE 173-7, 1999.

[18]. Samedov F, Durak M, Turkoglu AK. Photometric characterizations of light emitting diodes. In: Proceedings of the 2nd Balkan conference on lighting, Turkey, 150-5,2002.

[19]. Azizi M, Golmohammadi R, Aliabadi M. Comparative Analysis of Lighting Characteristics and Ultraviolet Emissions from Commercial Compact Fluorescent and Incandescent Lamps. J Res Health Sci.; 16(4):200-205,2016. [20]. Gloria SC, Sproul AB, Dain SJ. Performance of 'energy efficient' compact fluorescent lamps. Clin Exp Optom; 93(2):66-76.,2010.

[21]. International Commission on Illumination. Measurement of LEDs. CIE Publ. No.127:2007, Vienna: International Commission on Illumination;2007.

[22]. Manal A. Haridy, "Uncertainty Estimation of Spectral Mismatch Correction Factor for Incandescent Lamps", Int. J. Curr. Res. Aca. Rev; 3(7),pp. 262-273,2015.

[23]. Comission Internationale de Eclairage. Methods of characterizing Illuminance meters and luminance meters: performance, characteristics and specifications, CIE 69, 1987.

[24]. Samaa M. El-faramawy, Sameh M. Reda , Alaa Eldin Ahmed Abd- Elmaged, Rem H. El-gebaly, A. Soltan Monem "Radiometric Technique to Assess the Qualification of Phototherapy Luminaire for Jaundice Treatment", Medical Science, Volume 5, Issue :, pp. 428430,7 , July 2015.

[25]. International Electrotechnical Commission (IEC). Spectroradiometric measurement of light sources. Vienna: CIE Publication; 1984.

[26]. ASTM G138. Standard test method for calibration of a spectroradiometer using a standard source of irradiance. Pennsylvania: West Conshohocken; 2012.

[27]. International Organization for Standardization (ISO), Guide to the expression of uncertainty in measurement (1993).

[28]. United Kingdom Accreditation Service (UKAS), The expression of uncertainty and confidence in measurement, 2nd ed. (2007). 